\title{
OPEN GEODATA AND OPEN-SOURCE GIS IN THE CENTER FOR FOREST ECOLOGY AND PRODUCTIVITY OF THE RUSSIAN ACADEMY OF SCIENCES (CEPF RAS)
}

\author{
Ekaterina S. Podolskaia \\ Laboratory of Forest Ecosystems Monitoring, Center for Forest Ecology and Productivity of the Russian Academy of Sciences (CEPF RAS) \\ (ekaterina.podolskaia@gmail.com)
}

\begin{abstract}
KEY WORDS: Open Source, Open data, QGIS, OSM, transport accessibility, $\mathrm{CO}_{2}$ emission, forest management, interdisciplinary research
\end{abstract}

\begin{abstract}
:
Open data and Open-source tools are widely and globally used in the activities of research institutions. Particularity of scientific projects at the Center for Forest Ecology and Productivity of the Russian Academy of Sciences (CEPF RAS) includes ecology and productivity of forests in Russia. In order to emphasize and to develop the ecosystem functions, resources and environmental potential of Russian forests the Center uses geoinformational and remote sensing methods and tools. Logistically complex and economically costly ground access to the forest fires and forest resources is the specific feature of Russian forest domain. Open Data and Open Source tools have an essential methodological, technological meaning, as well as a potential for the forestry challenges in the country. We present an Open GeoData and Open Source GIS's experience of ongoing activities devoted to the transport modelling (transport accessibility in the forests and emission of carbon dioxide). An "Open"-research direction extends the activities of the "Transportation Task" group by implementing OSM and QGIS with its plugins. CEPF popularizes Open data and Open Source in their geo-applications by giving lectures and publishing papers in the "Forest Science Issues" interdisciplinary journal.
\end{abstract}

\section{INTRODUCTION}

Forestry is an industry that deals with the reproduction and protection of forests, regulation and accounting of forest resources. Open data are collected, maintained and published by regional administrations and government in Russia, they still cover the country's territory partially only, exist in non-spatial formats and often are not updated for some certain time frames. There is a great importance and necessity of an updated Open geospatial data and Open Source tools for the projects in Russian forestry nowadays. Open Data and Open Source are used in the preparation and assessment of seasonal fire hazards and logging of forest resources in the forestry units and forest departments, for the development of regional programs and Forest Plans for the years to come. The Russian Forest Code of 2006, an official document for the forest industry and forest management in Russia, is an unaltered legal base with all its constant updates of forest terminology and forest data sources.

\section{RESEARCH, EDUCATIONAL AND PUBLISHING} DIRECTIONS

\subsection{Transport modelling to access the forest fires and forest resources with Open Data and Open Source}

Ensuring ground transport access to the forest resources and forest fires through the development of transport infrastructure facilities continues to be an urgent challenge of Russian economy with its modern specifics (legislative, financial, logistics, insurance, etc.). Transport accessibility is one of the types of accessibility, along with its economic and industrial types, which is determined by the density of transit routes consisting of navigable rivers and railways, federal and regional highways. Public and forest roads, as well as forest clearings as a part of the forest infrastructure have a significant impact on the environment.
Forest roads and clearings are a very important asset for the transport accessibility in the forests. According to the Forest Code of Russia, forest roads can be created for any type of forest usage, as well as for the forests protection and reproduction. Forest roads are usually consider as linear road infrastructure facilities. In Russian practice, they are subdivided into logging roads and forestry roads according to their purpose. The presence and condition of forest roads continues to be one of the challenges of Russian forest management.

Open Street Map (OSM), a widely used data source, including forestry domain, has a different quality and completeness for the objects' attributes and geometry at the global extent and, in particular, within the territory of Russian Federation. At the same time, it has the value of up-to-day and freely accessible set of polygons, points and polylines for mapping geographical objects. OSM classification has a category combining "agricultural field roads, forest roads, unofficial dirt roads", which are designated as a track (mostly used for agriculture, forestry, outdoor recreation, and similar activities on open land) and in most cases means "a driving direction".

Using OSM, researchers undertake a comparative data analysis, and their results are of particular interest for the remote areas on the planet, such as, for instance, Siberia in Russia. It was shown that for the extent of Irkutsk region (Siberian Federal District) the total length of all roads and forest clearings of 1: 200000 scale from old digital maps is larger than OSM dataset of the same extent (Podolskaia et al, 2020b). Analysis of OSM data for other regions confirms the fact that there is a certain lack of forest road infrastructure (forest roads and glades). In the mentioned paper OSM vector data (dated of approximately 2000) compared to the actual OSM datasets (2021) shown just roads with improved coverage and highways (in Russian classification) were kept unchangeable in terms of geometry. Practically for the Russian regions, OSM has to be 
used in combination with other specific datasets to produce a reliable data product like a forest infrastructure database; its assessment for a certain area should be a regular and recurrent activity in the management of any GIS-project.

The topic of ground transport accessibility of forest fires and forest resources (which have their own specific features like urgency of being at the place of the forest fire) is presented in the series of papers (Podolskaia et al., 2019, 2020a, 2020b). To continue it we have turned to the investigation of GIS Open Source applications searching for the tools to obtain additional characteristics of access routes.

Current leading role for Open Source software in scientific research belongs to the QGIS software application (Quantum GIS) with its plugins library (or web portal) at (https://plugins.qgis.org/plugins/). Plugins are the software modules developed to expand the standard functionality of a QGIS application for Desktop and WEB projects, to solve a specific spatial thematic problem using custom or predefined set of data, services, classifications, and formats. Variety and complexity of QGIS-plugins written in different languages are constantly growing, and, at the same time, there is still a limited set of forest-related tools to work with the forest data.

We are regularly reviewing the tools of actual versions of QGIS 3.x for the forestry. One of "the oldest" is the landscape ecology statistics plugin, or LecoS (Landscape Ecology Statistics, https://plugins.qgis.org/plugins/LecoS/), which has been available since QGIS version 1.8. It uses Python libraries SciPy and Numpy to calculate basic and additional landscape analysis metrics sourced from the FRAGSTATS software.

Among the available plugins there are some modules under the "experimental" status, an example is a tool to build a route network for accessing forest resources and forest fires (LCPNetwork, https://plugins.qgis.org/plugins/LCPNetwork/). It uses the classic for transport applications Dijkstra algorithm to produce an optimal route between objects of two point vector layers. The result of the plugin's work is an accumulated cost map for each of the points and a linear layer of traffic routes.

An ability to keep and access the historical data is an essential feature for the forestry so far it usually works with long-term datasets. In this regards, a QGIS-plugin example is the NAFI Fire Maps project for Australia, which in addition to the up-todate data provides access to an archive. This tool became an extension of a web gis-project (https://www.gaiaresources.com.au/fire-mapping-qgis-plugin/).

Thus, the niche of thematic forest tasks in the modern QGIS plugins repository continues to be quite small. Transport and environmental applications implemented in the form of QGIS tools are more numerous. In terms of number and content published plugins are very heterogeneous to compare with each other; it is difficult to make any assumptions about actual trends in the development and functionality of tools for the forest fires and forest resources management. Shp-file remains the main working format for the desktop QGIS, some data are available in the WMS service format, which is supported by other Open Source or commercial GIS-applications. Functionality of plugins could be reviewed on a regular basis following new versions of QGIS. Currently plugins development, publishing and testing by QGIS-users continues to be a very dynamic process.

\section{2 $\mathrm{CO}_{2}$ emission in transport modelling with Open Source}

It is generally accepted that climate change is a modern global challenge, to which a lot of research has been dedicated, some recent papers in the forest domain are (Lukina et al., 2020; Leskinen et al., 2021). There are some known and actively developing global projects for the placement, study and display of modern data on carbon fluxes as a result of natural processes and human activities on a regional and global scale, an example is the Global Carbon Atlas; http://globalcarbonatlas.org/ru / content / project-overview). The issue of carbon dioxide emissions is related to the transport accessibility in various domains (Wenz et al., 2020). Estimation of $\mathrm{CO}_{2}$ emissions continues to be a widely studied topic in Russia especially in the forestry.

Modern methods and technologies of geoinformatics, using Open Data and developments based on Open Source, the description of which is presented in the work (Lovelace, 2021), already have some solutions to calculate $\mathrm{CO}_{2}$ emissions for the vehicles of different types moving along the different types of terrain. Open data on $\mathrm{CO}_{2}$ emissions in different countries of the world are collected in such projects as "Data on $\mathrm{CO}_{2}$ and Greenhouse Gas Emissions by Our World in Data (https://github.com/owid/co2-data; https://github.com/ datasets / co2-fossil-global).

An interesting developing project of recent years "VEIN: An R package for vehicular emissions inventories" (https://www.researchgate.net/project/VEIN-An-R-package-forvehicular-emissions-inventories) simulates the volume of carbon dioxide emissions gas of the traffic flow within a city based on the vehicle's parameters and the fuel it uses. Some tests were made to simulate emissions for a set of atmospheric pollutants (Gavidia-Calderon et al., 2020) using this module.

The current Open Source QGIS Road Emission Calculator, developed according to the EU standards by the Norwegian Public Roads Administration calculates the amount of $\mathrm{CO}_{2}$ emissions along a route between two points, having previously configured a model for vehicle type, parameters and fuel (https://plugins.qgis.org/plugins/RoadEmissionCalculator/). The plugin has "non-experimental" status (as of 15/06/2021) and is an example of a ready-to-test geoinformation module in QGISenvironment.

Methodology of papers (Podolskaia et al., 2019, 2020a) and QGIS-tools we have mentioned in the paper are currently used to elaborate the ecological and economical aspects of transport accessibility in the forests. In addition to the three parameters (time, average speed and length), the volume of carbon dioxide emission along the access route will be a comprehensive environmental assessment of heavy vehicle's move. Regional calculations along the routes can be timed to coincide with the regional $\mathrm{CO}_{2}$ emissions of a particular constituent administrative entity (or a Federal District) of Russia and provide some certain assessment of forestry's activity, its contribution to the total emission of carbon dioxide in the region. 


\subsection{Educational and publishing activities}

Besides research, CEPF popularizes Open data and Open Source in geoinformatics by doing educational events like lectures for the Russian forest industry's community proposing and promoting its advantages and reliability.

Our contribution to the Open Data and Open Source also includes publishing papers in the "Forest Science Issues" interdisciplinary scientific journal devoted to the forest science.

Practical questions of working with QGIS Desktop and Server summarized in the book for Russian-speaking QGIS-users (Podolskaia, 2020) will be extended in depth and presented with the GIS-cases in the forest domain.

\section{KEY AREAS}

Key model areas are located in the different parts of the country where the Center is conducting its research projects and collaborations with the forest institutions and reserved areas. They are the following: Nizhegorodskaia oblast (region), Krasnoyarsk Region, Irkutsk and Novosibirsk Regions, and Siberian Federal District. These areas are of quite different spatial extent depending on the project. The majority of them has a constant and severe forest fire activity and other challenges related to the forests.

\section{CONCLUSIONS}

Ongoing transport modelling researches at the Center links transport infrastructure, $\mathrm{CO}_{2}$ emissions of heavy transport (forest trucks), forestry and geoinformatics.

Access routes of forest fire brigade or logging team's movement along the roads in Russia often characterize by a long distance journey and consequently is a time-consuming task in operational wildfire response planning. The movement of special heavy vehicles along the roads and clearings is also a challenge in terms of $\mathrm{CO}_{2}$ emissions. In this case, the environmental component affects the optimality of the constructed route; the value of carbon dioxide emissions can be added to the route's characteristics.

Ecological and infrastructural assessments of accessing the forest fires and forest resources using modern methods and technologies of geoinformatics will continue to advance in understanding climate change at different spatial levels. The project is being developed in the interdisciplinary working group "Mapping ecosystem services of forests", created at the CEPF RAS in February 2021.

\section{ACKNOWLEDGEMENTS}

The research was conducted under the contract with state funding "Methodological approaches to assessing the structural organization and functioning of forest ecosystems", state registration number - AAAA-A18-118052590019-7.

\section{REFERENCES}

Gavidia-Calderon, M. E., Ibarra-Espinosa, S., Kim, Y., Zhang, Y., and de Fatima Andrade, M., 2020. Simulation of O3 and NOx in Sao Paulo street urban canyons with VEIN (v0.2.2) and MUNICH (v1.0). https://doi.org/10.5194/gmd-2020-282. Preprint. 14 November 2020
Leskinen, P., Lindner, M., Verkerk, P.J., Nabuurs, G.J., Van Brusselen, J., Kulikova, E., Hassegawa, M. and Lerink, B. (eds.), 2020. Russian forests and climate change. What Science Can Tell Us 11. European Forest Institute.

https://doi.org/10.36333/wsctu11

Lovelace, R., 2021. Open source tools for geographic analysis in transport planning. $J$ Geogr Syst., 1-32. DOI: 10.1007/s10109-020-00342-2

Lukina, N. V., Geraskina, A.P., Gornov, A.V., Shevchenko, N.E., Kuprin, A.V., Chernov, T.I., Chumachenko, S.I., Shanin, V. N., Kuznetsova, A.I., Tebenkova, D.N., Gornova, M.V., 2020. Biodiversity and climate regulating functions of forests: current issues and prospects for research. Forest Science Issues, 3 (4), 1-90. DOI 10.31509/2658-607x-2020-3-4-1-90.

Podolskaia, E. S., Kovganko, K. K., Ershov, D. V., Shulyak, P. P., and Suchkov, A. I., 2019. Using of transport network model to estimate travelling time and distance for ground access a forest fire. Forest Science Issues, 2 (1), 1-24. DOI 10.31509/2658-607x-2019-2-2-1-22.

Podolskaia, E., 2020. Basics of working in Open Source QGIS: geodata, coordinates, functionality, data quality control, map design and web-publishing. Manual, Lab-publisher, 52.

Podolskaia, E., Ershov, D. and Kovganko, K., 2020a. GISApproach to Estimate Ground Transport Accessibility of Forest Resources (Case Study: Novosibirsk Region, Siberian Federal District, Russia). Journal of Geographic Information System, 12, 451-469. doi: 10.4236/jgis.2020.125027.

Podolskaia, E., Ershov, D., Kovganko. K., 2020b. Comparison of data sources on transport infrastructure for the regional forest fire management. Reyer, C., Bilogub, M., Mahnken, M., Gutsch, M., Kruger, K., Ramming, A., Reineking, B., Seidl, R., Schelhaas, M.-J., Makela, A., Verkerk, H. (Eds.). Book of abstracts, Managing forests in the $21^{\text {st }}$ century, Conference at the Potsdam Institute for Climate Impact Research (Potsdam 2020), 59. https://doi.org/10.2312/pik.2020.002

Wenz, L., Weddige, U., Jakob, M., Steckel, J.C., 2020. Road to glory or highway to hell? Global road access and climate change mitigation. Environmental Research Letters, 15. https://dx.doi.org/10.1088/1748-9326/ab858d 